\title{
Down's syndrome: an atheroma-free model?
}

\author{
J C MURDOCH, J CHRISTINE RODGER, S S RAO, C D FLETCHER, M G DUNNIGAN
}

British Medical fournal, 1977, 2, 226-228

\section{Summary}

Postmortem examination of five institutionalised patients with Down's syndrome (DS) aged 40-66 years showed a complete absence of atheroma, while a similar number of mental defectives without DS were found to have mild or severe atheroma. Previous investigation of risk factors for atheroma in 70 patients with DS and 70 ageand sex-matched mental defectives living in the same institution showed significantly lower systolic and diastolic blood pressures in the DS group, with the exception of systolic pressure in men under 40. Fasting serum cholesterol and triglyceride concentrations were similar in the two groups, but triglyceride concentrations were significantly lower than in normal people without a history of vascular disease. These unexplained observations may be relevant in further studies of the pathogenesis of atheroma.

\section{Introduction}

The most striking feature of any population with Down's syndrome (DS) in an institution is that few such patients survive beyond 60 . Richards ${ }^{1}$ stated that this is the result of an increased mortality in the fifth and sixth decades, which is as yet unexplained. A review by one of us (J C M) of the death certificates of 21 institutionalised patients with DS suggested that in 11 cases $(52 \%)$ the cause of death was cardiovascular (congestive cardiac failure, primary cause unspecified, in five; coronary thrombosis in four; cerebral thrombosis in one; and systemic hypertension in one). We therefore decided to examine the evidence for atherosclerosis and particularly for ischaemic heart disease in institutionalised patients with DS.

\section{Subjects and methods}

Seventy institutionalised patients in whom the diagnosis of DS had been established by chromosome analysis were studied; patients with hypothyroidism ${ }^{2}$ were excluded. Thirty-seven were men aged 21-59 (mean 38) years, and 33 were women aged 18-64 (mean 41) years. An age- and sex-matched control group of 70 non-mongol mentally deficient patients was selected from the same hospital. All were on a normal diet. Two patients with DS and 13 of the controls were cigarette smokers.

Patients with DS were examined clinically and underwent chest radiography. In seven the findings were diagnostic of congenital heart disease, and in six suggestive. Resting supine blood pressure was measured in all patients studied with a mercury sphygmomanometer.

Lennox Castle Institution, Lennoxtown, by Glasgow

J C MURDOCH, MB, MRCGP, visiting general practitioner (now senior lecturer, Department of General Practice, University of Dundee)

Stobhill General Hospital, Glasgow G21 3UW

J CHRISTINE RODGER, MD, MRCP, senior registrar (now consultant physician, Monklands District General Hospital, Airdrie ML6 0JS)

S S RAO, MB, MRCPATH, consultant pathologist

C D FLETCHER, BSC, biochemist

M G DUNNIGAN, MD, MRCP, consultant physician
The fourth-phase muffle was taken as the diastolic end-point. The results were compared by means of Student's $t$ test.

A resting 12-lead electrocardiogram (ECG) was recorded in 62 of the patients with DS. The ECGs were read by one observer and classified according to the Minnesota code. ${ }^{3}$ The following findings were regarded as evidence of myocardial ischaemia: Q/QA waves (codes 1.1-3), S-T depression (codes 4.1-3), $\mathrm{T}$-wave inversion or flattening (codes 5.1-3), or left bundle-branch block.

Fasting serum cholesterol and triglyceride concentrations were measured in 34 men and 29 women with DS and in the same number of controls. Serum cholesterol was measured according to Annan and Isherwood's method, ${ }^{4}$ and serum triglycerides were estimated on an AutoAnalyzer. The results were compared with fasting serum lipid concentrations obtained as part of a previous, unpublished study of 123 normal people aged 20-65 who had no family history of vascular disease and were living at home. The frequency distribution of the results was analysed and the $\chi^{2}$ value calculated.

Postmortem examination was carried out on five patients with DS who died during the study. Three were men aged 60,56 , and 40 years, and two were women aged 66 and 44. Over the same period necropsy was performed on five non-mongol patients from the same hospital, two men aged 60 and 42 years, and three women aged 80, 71, and 56 years.

\section{Results}

With the exception of men under 40, systolic and diastolic blood pressures were significantly lower in the DS group than in the controls (table I). In the DS group blood pressure did not rise significantly with age. No patient in the DS group was hypertensive, and all were in sinus rhythm (rate 48-105 (mean 73) beats/min). No patient had major ECG evidence of infarction (codes 1.1-3) or ischaemia (codes 5.1-2 and 7.1). In patients without congenital heart disease only minor abnormalities were present, and evidence of possible myocardial ischaemia was restricted to $0.5-\mathrm{mm} \mathrm{S}$-T depression (code 4.2) in one case and non-specific T-wave flattening (code 5.3) in seven others.

Serum cholesterol and triglyceride concentrations in the DS and control groups were not significantly different. Serum lipid concentrations, however, were significantly lower in both groups of patients than in the group of normal people living at home (table II). Twelve euthyroid patients with DS $(19 \%)$ and 14 non-mongol controls $(22 \%)$ showed moderate hypercholesterolaemia, with values exceeding $6.4 \mathrm{mmol} / \mathrm{l}(247 \mathrm{mg} / 100 \mathrm{ml})$.

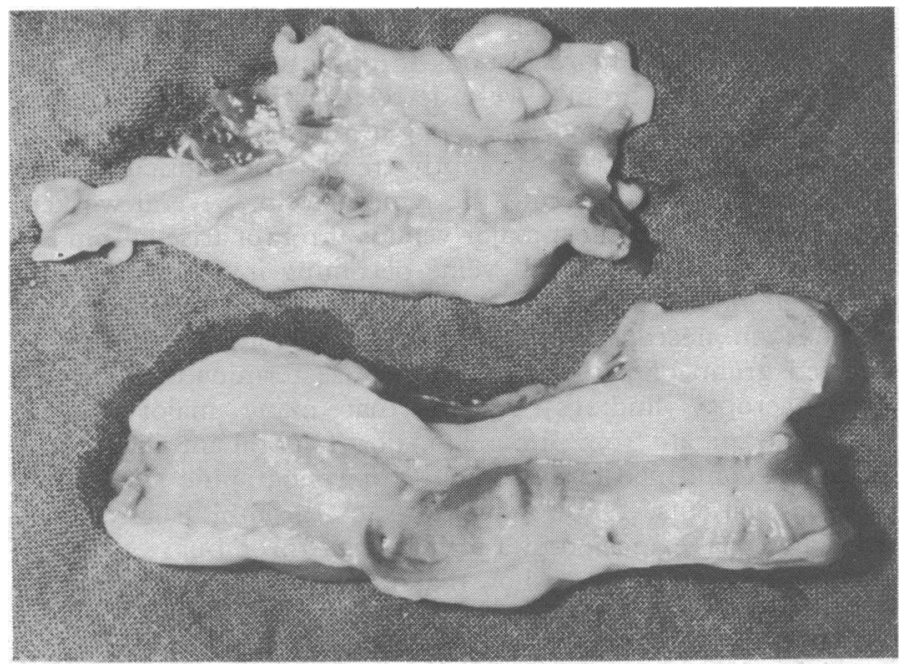

FIG 1 -Coronary arteries from 60-year-old patient with Down's syndrome showing no atheroma. 
TABLE I-Mean $( \pm S D)$ systolic and diastolic blood pressures (mm $\mathrm{Hg}$ ) in patients with Down's syndrome and non-mongol mental defectives

\begin{tabular}{|c|c|c|c|c|c|c|}
\hline \multirow{2}{*}{ Sex } & \multicolumn{2}{|c|}{ Down's syndrome } & \multicolumn{2}{|c|}{ Mental defectives } & \multicolumn{2}{|c|}{ Significance* } \\
\hline & Systolic & Diastolic & Systolic & Diastolic & Systolic & Diastolic \\
\hline \multicolumn{7}{|c|}{ Age $40-65$ years } \\
\hline $\begin{array}{l}M(n=17) \\
F(n=20)\end{array}$ & $\begin{array}{l}110 \cdot 6 \pm 30 \cdot 1 \\
117 \cdot 3 \pm 23.1\end{array}$ & $\begin{array}{l}67 \cdot 5 \pm 9 \cdot 5 \\
71 \cdot 8 \pm 11 \cdot 2\end{array}$ & $\begin{array}{l}135 \cdot 1 \pm 21 \cdot 3 \\
142 \cdot 3 \pm 32 \cdot 0\end{array}$ & $\begin{array}{l}87 \cdot 1 \pm 10 \cdot 8 \\
86 \cdot 2 \pm 15 \cdot 7\end{array}$ & $\begin{array}{l}P<0.01 \\
P<0.001\end{array}$ & $\begin{array}{l}\mathrm{P}<0.01 \\
\mathrm{P}<0.001\end{array}$ \\
\hline \multicolumn{7}{|c|}{ Age 20-39 years } \\
\hline $\begin{array}{l}M(n=20) \\
F(n=13)\end{array}$ & $\begin{array}{l}114.0 \pm 22.4 \\
112.9 \pm 14.8\end{array}$ & $\begin{array}{l}68 \cdot 1 \pm 13 \cdot 8 \\
68 \cdot 3 \pm 11 \cdot 0\end{array}$ & $\begin{array}{l}123 \cdot 0 \pm 22 \cdot 2 \\
122 \cdot 7 \pm 12 \cdot 3\end{array}$ & $\begin{array}{l}85 \cdot 2 \pm 11 \cdot 0 \\
76 \cdot 6 \pm 10 \cdot 5\end{array}$ & $\begin{array}{l}\text { NS } \\
\mathbf{P}<0.05\end{array}$ & $\begin{array}{l}P<0.001 \\
P<0.05\end{array}$ \\
\hline
\end{tabular}

*Assessed with Student's $t$ test.

NS $=$ Not significant.

TABLE II-Mean serum cholesterol and triglyceride concentrations (mmol/l) in patients with Down's syndrome, normal people without history of vascular disease, and non-mongol mental defectives. (Ranges given in parentheses)

\begin{tabular}{|c|c|c|c|c|c|c|c|c|}
\hline & & & & & \multicolumn{2}{|c|}{ Serum cholesterol } & \multicolumn{2}{|c|}{ Serum triglyceride } \\
\hline & & & & & Age $20-39$ years & Age 40-65 years & Age $20-39$ years & Age 40-65 years \\
\hline \multicolumn{4}{|c|}{$\begin{array}{l}\text { Patients with Down's syndrome (A) } \\
\text { Normal people (B) } \\
\text { Mental defectives (C) } \\
\text { Me }\end{array}$} & $\begin{array}{l}\cdots \\
\cdots \\
\cdots\end{array}$ & $\begin{array}{l}5 \cdot 30(2 \cdot 84-6 \cdot 86) \\
5 \cdot 64(4 \cdot 27-7 \cdot 25) \\
5 \cdot 44(3 \cdot 24-7 \cdot 64)\end{array}$ & $\begin{array}{l}5.82(4 \cdot 27-8 \cdot 03) \\
6.50(3 \cdot 49-10 \cdot 87) \\
5.95(3 \cdot 49-10 \cdot 31)\end{array}$ & $\begin{array}{l}0.96(0.50-2.03) \\
1.22(0.56-6.10) \\
0.99(0.45-1.97)\end{array}$ & $\begin{array}{l}0.98(0.45-1.92) \\
1.42(0.93-3.78) \\
1.07(0.50-1.58)\end{array}$ \\
\hline 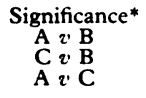 & $\begin{array}{ll} & \\
\ldots & \ldots \\
\ldots & \ldots \\
\ldots & \end{array}$ & $\begin{array}{l}\cdots \\
\cdots \\
\cdots\end{array}$ & $\begin{array}{l}\cdots \\
\cdots \\
\cdots\end{array}$ & $\begin{array}{l}\cdots \\
\cdots \\
\cdots\end{array}$ & $\begin{aligned} & P<0.01 \\
& \text { NS } \\
& \text { NS }\end{aligned}$ & $\begin{array}{l}\mathrm{NS} \\
\mathrm{P}<0 \cdot 05 \\
\mathrm{NS}\end{array}$ & $\begin{array}{l}\mathrm{P}<0.005 \\
\mathrm{P}<0.05 \\
\mathrm{NS}\end{array}$ & $\begin{array}{l}P<0.001 \\
P<0.001 \\
\quad \text { NS }\end{array}$ \\
\hline
\end{tabular}

*Assessed with $\%$ test.
Conversion: SI to traditional units-Serum cholesterol: $1 \mathrm{mmol} / 1=38.6 \mathrm{mg} / 100 \mathrm{ml}$. Serum triglyceride: $1 \mathrm{mmol} / 1 \approx 88.5 \mathrm{mg} / 100 \mathrm{ml}$.

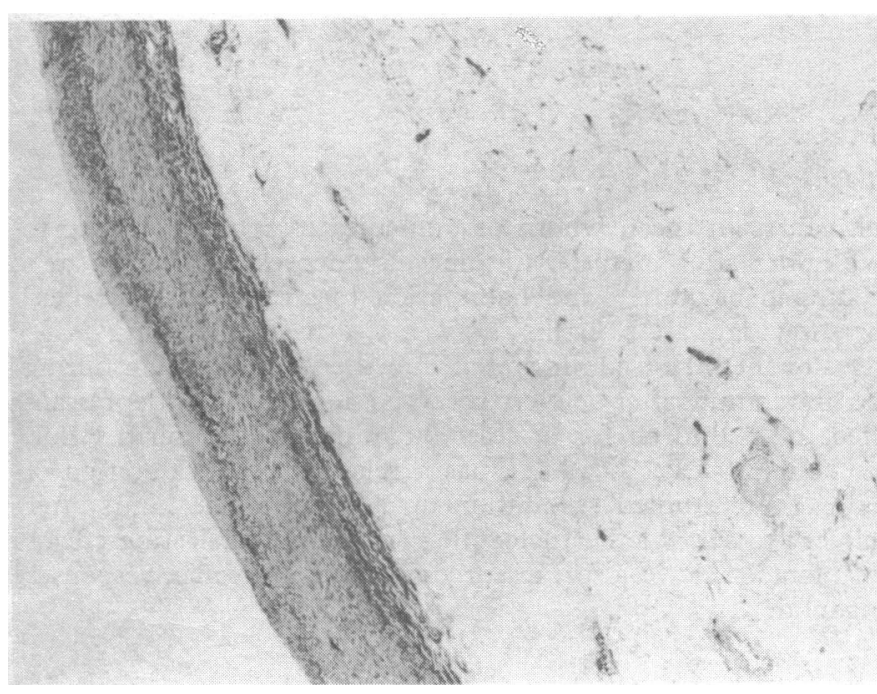

FIG 2-Section of coronary artery showing normal arterial wall with slight diffuse intimal thickening. (Elastic van Gieson.)

Necropsy showed that in three patients with DS the cause of death was bronchopneumonia: one of these had a carcinoma of the maxillary antrum. In the remaining two patients the cause of death was massive pulmonary embolism associated with deep vein thrombosis in both legs. In the five non-mongol mentally deficient patients who came to necropsy the cause of death was bronchopneumonia.

Atherosclerosis was absent throughout the cardiovascular systems of all five patients with DS who came to necropsy. The coronary arteries were macroscopically free of atheroma (fig 1), and microscopy showed only slight, diffuse intimal thickening that was normal for age (fig 2). The aorta and iliac, femoral, carotid, and cerebral arteries were also completely free of macroscopic atherosclerosis: in two cases a few fatty streaks were seen at the origin of the main aortic branches. Microscopy showed total absence of atherosclerosis in the aorta and a noticeable reduction in elastic fibres in the media (fig 3). The iliofemoral system and extracranial and renal arteries all showed mild to moderate reduction in elastic fibres, and again there was no histological evidence of atherosclerosis. In contrast, all five of the non- mongol patients showed evidence of atherosclerosis in the aorta and iliac-femoral, carotid, and coronary arteries. In the two youngest patients it was mild and confined to fibrofatty plaques, and in the others there was severe atherosclerosis with ulceration and calcification. In two patients both coronary arteries and their main branches showed severe calcified atherosclerosis with stenosis but without occlusion. In the other three there was a moderate degree of atheroma in both coronary arteries and their main branches without stenosis or occlusion.

\section{Discussion}

The most impressive finding of this study was the complete absence of atherosclerosis in the five patients with DS examined post mortem. The ECGs provided no evidence of myocardial infarction and no convincing evidence of ischaemia in this group of patients with DS. These observations suggest that

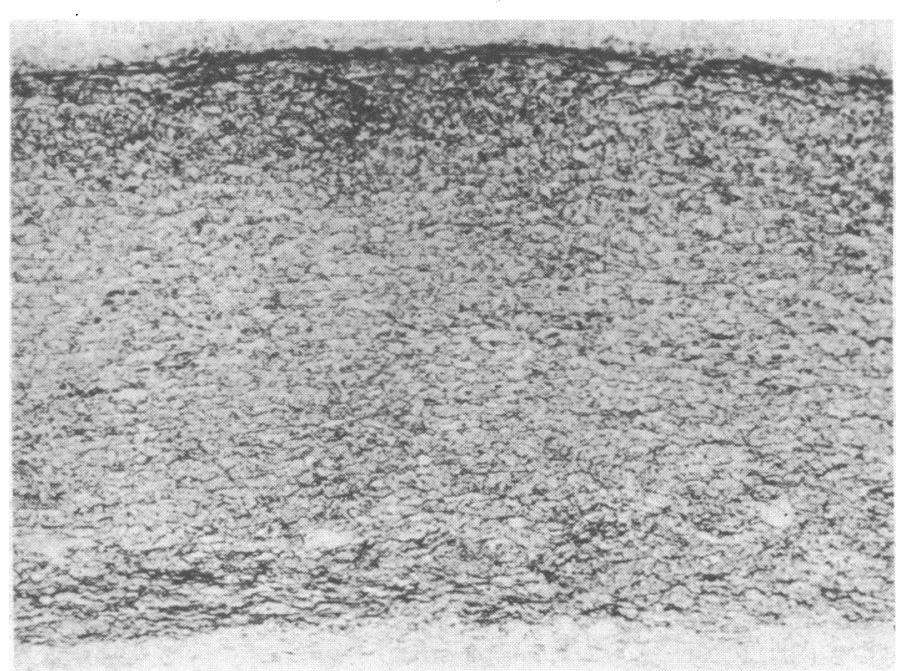

FIG 3-Section of descending aorta showing absence of atheroma and noticeable reduction of elastic fibres in media. (Elastic van Gieson.) 
this group in particular, and perhaps patients with DS in general, show a remarkable freedom from the atherosclerosis that, in some degree, inevitably accompanies advancing age. The reasons are not clear. The finding of atherosclerosis in the non-mongol mental defectives suggests that environmental factors such as diet, composition of the water, and the absence of stress are not responsible. Furthermore, the differences between the groups cannot be explained on the basis of lipid concentrations: at the time of study both groups had lower serum lipid concentrations than a group of normal people.

Of the remaining accepted risk factors, blood pressure was slightly but significantly lower in the DS group, and only two of these patients $(3 \%)$ smoked compared with $13\left(19^{\circ}{ }_{0}\right)$ of the controls. While these findings may partly explain the necropsy evidence, it is difficult to accept that they can account for the total absence of atheroma in the DS group and its presence in the controls to a degree consistent with that usually found in the general population.

Probably there are unidentified factors peculiar to DS that confer a noticeable freedom from atherosclerosis. Whether these are haemodynamic or arise from a peculiarity of vessel wall morphology is speculative. It certainly appears on the present evidence that DS provides an atherosclerosis-free model that merits further study.

We thank Dr R C MacGillivray for advice and encouragement, and Dr M S Newton and Mrs J Taylor, MRC Clinical and Population Cytogenetics Unit, for the chromosome studies.

J C M was in receipt of a grant from the Mental Health Foundation (Scottish Division).

\section{References}

1 Richards, B W, editor, in Mental Subnormality: Modern Trends in Research, p 54. London, Pitman, 1970.

${ }^{2}$ Murdoch, J C, et al, Fournal of Clinical Endocrinology, 1977, 44, 453.

${ }^{3}$ Blackburn, H, et al, Circulation, 1960, 21, 1160.

4 Annan, R, and Isherwood, E M, fournal of Medical Laboratory Technology, 1969, 26, 202.

(Accepted 20 May 1977)

\title{
CONDENSED REPORTS
}

\section{Effects of naloxone on pethidine-induced neonatal depression}

\author{
P C WIENER, M I J HOGG, M ROSEN
}

\section{Part I-Intravenous naloxone}

British Medical fournal, 1977, 2, 228-231

\section{Summary}

Infants whose mothers had had pethidine during labour were given either naloxone $40 \mu \mathrm{g}$ or isotonic saline administered intravenously double-blind within one minute of birth. Peak alveolar carbon dioxide tension, carbon dioxide excretion, alveolar ventilation, feeding behaviour, and habituation to a specific sound stimulus were measured regularly up to 48 hours after birth. Alveolar carbon dioxide tension was significantly lower and alveolar ventilation significantly higher half an hour after birth in the naloxone-treated group than in the saline-treated group, but these differences between the groups were not significant at any other time, and there were no significant differences in sucking frequency or pressure, milk consumption, or habituation to the auditory stimulus.

\section{Introduction}

Administering pethidine to a mother in labour slows down her infant's recovery from birth asphyxia, ${ }^{1}$ lowers oxygen saturation, ${ }^{2}$ and prolongs the time to sustained respiration. ${ }^{3}$ Furthermore, pethidine increases neonatal arterial $\mathrm{PCO}_{2}$ over

Department of Anaesthetics, University Hospital of Wales, Cardiff CF4 4XW

P C WIENER, MD, FFARCs, senior registrar

M I J HOGG, BSC, physicist

M ROSEN, MB, FFARCS, consultant the values in the newborn of unmedicated mothers for up to five hours after birth. ${ }^{4}$ Pethidine also depresses the neonate's feeding behaviour ${ }^{56}$ and habituation to an orientating reflex ${ }^{7}$ for a few days after birth.

Naloxone $40 \mu \mathrm{g}$ administered into the umbilical vein during the first minute after delivery reverses the respiratory depressant effect of pethidine for at least 30 minutes after birth. ${ }^{8}$ But, naloxone, at least in adults, has a relatively short duration of action. ${ }^{9}$ We studied respiration up to the first 48 hours after delivery to see whether naloxone had any longer-lasting effects in infants and we also measured feeding and reflex responses to sound.

\section{Methods}

Written consent was obtained from mothers before labour. Those studied had received pethidine (100-300 mg) during labour. Some had also had $10 \mathrm{ml}$ of $1 \%$ lignocaine infiltrated into the perineum before delivery. Naloxone $(40 \mu \mathrm{g}$ in $1 \mathrm{ml})$ or placebo $(1 \mathrm{ml}$ isotonic saline), chosen blind at random, was administered into the umbilical vein within one minute of birth. The infants included were those of 38-42 weeks' maturity, born spontaneously or after easy forceps delivery, with an Apgar score greater than 7 at one minute, and an umbilical venous $\mathrm{pH}$ greater than $7 \cdot 25$ at birth. Blood was taken from a maternal vein and the umbilical vein at birth. Plasma pethidine concentration was measured by gas chromatography.

The newborn infants were transferred from the labour room to a nursery in which the temperature, lighting, and background noise were constant. Measurements were made (by PCW) half an hour and $4,8,12,24$, and 48 hours after birth. (Feeding started at four hours). Peak alveolar carbon dioxide concentration and carbon dioxide excretion were measured using a rapid-response infrared carbon dioxide analyser (Beckman LB-2) coupled to a peak-hold meter and integrator. ${ }^{10}$ Alveolar ventilation (body temperature and pressure, saturated) and carbon dioxide tension were derived from these measurements. 